\title{
TRATAMENTO DE LESÕES DE CÁRIE PROFUNDA COM RISCO DE EXPOSIÇÃO PULPAR - DECISÃO BASEADA EM EVIDÊNCIAS
}

\section{TREATMENT OF DEEP CARIE LESIONS WITH PULP EXPOSURE RISK - EVIDENCE BASED DECISION}

\author{
Vivian Caroline Brazolino Valentim* \\ Daniela Nascimento Silva" \\ Martha Chiabai Cupertino Castro***
}

\begin{abstract}
RESUMO
O objetivo do presente estudo foi investigar na literatura as evidências disponíveis sobre o tratamento de lesões de cárie profundas em dentes permanentes, estabelecendo análises comparativas, sintetizando o conhecimento e incorporando a aplicabilidade dos resultados de estudos significativos na prática diária. Pesquisou-se o grau de risco de exposição pulpar nas técnicas: Remoção Total da cárie, Tratamento Expectante e a Remoção Seletiva da cárie. Adotou-se a revisão integrativa da literatura como referencial teórico-metodológico da Prática Baseada em Evidências e organizada em seis etapas: Identificação do tema e seleção da questão de pesquisa; Estabelecimento de critérios para inclusão e exclusão de estudos; Busca na literatura; Definição das informações a serem extraídas dos estudos selecionados; Avaliação e interpretação dos resultados; Síntese do conhecimento. Foram identificados 5.342 artigos científicos com os descritores Cárie Dentária e Restauração Dentária Permanente. Com a adição da palavra-chave Tratamento Expectante e após a aplicação dos critérios de inclusão e exclusão, a amostra totalizou 16 periódicos compreendidos no período entre 1996 e 2016. Conclui-se que a Remoção Total da cárie foi considerada um procedimento muito invasivo e desnecessário em casos de dentes vitais com ausência de patologias, dado o elevado grau de exposição pulpar. Baseado nos princípios da Odontologia Minimamente Invasiva, as técnicas de Tratamento Expectante e Remoção Seletiva da cárie são formas de intervenção mais seguras e eficazes associadas ao controle do biofilme cariogênico para inativação das lesões de cárie, de modo a evitar o ciclo restaurador e prolongar a presença dos dentes na cavidade bucal.
\end{abstract}

Descritores: Cárie Dentária • Restauração Dentária Permanente • Odontologia Baseada em Evidências.

\section{ABS TRACT}

The aim of the present study was to investigate in the literature the available evidence of deep caries lesions treatment in permanent teeth, establishing comparative analysis, synthesizing knowledge and incorporating the applicability of the results of significant studies into daily practice. The degree of pulp exposure risk was searched in the techniques: Total Caries Removal, Expectant Treatment and Selective Removal of Carious. The integrative literature review was adopted as a theoretical-methodological reference of the Practice Based in Evidence and organized in six stages: Identification of the topic and selection the research question; Establishment of criteria for inclusion and exclusion of studies; Search in literature; Definition of the informations to be extracted from the selected studies; Evaluation and interpretation of results; Synthesis of knowledge. A total of 5.342 scientific articles were identified with descriptors Dental Caries and Permanent Dental Restoration. In the addition of the key word Expectant Treatment and after the inclusion and exclusion criteria was applied, the sample totaled 16 periodicals between 1996 and 2016. It was concluded that Total Caries Removal was considered a very invasive and unnecessary procedure in cases of vital teeth with absence of pathologies, taking into account the high degree of pulpal exposure. Based on Minimally Invasive Dentistry principles, Expectant Treatment and Selective Removal of Carious techniques are safer and more effective intervention forms associated with the control of cariogenic biofilm for inactivation of caries lesions, so as to avoid the restorative cycle and prolong the presence of teeth in the oral cavity.

Descriptors: Dental Caries • Dental Restoration, Permanent • Evidence-Based Dentistry

\footnotetext{
* Graduada em Odontologia - Universidade Federal do Espírito Santo. Vitória/ES. Email: vivian valentim@hotmail.com

** Doutora em Odontologia pela Pontifícia Universidade Católica do Rio Grande do Sul/RS. Professora do Departamento de Clínica Odontológica da Universidade Federal do Espírito Santo, Vitória/ES. Email: nascimentosilva.daniela@gmail.com

*** Doutora em Odontologia pela Universidade do Estado do Rio de Janeiro/RJ. Professora do Departamento de Prótese Dentária da Universidade Federal do Espírito Santo. Vitória/ES. E-mail: marthachiabai@gmail.com
} 
VALENTIM VCB

$S I L V A \quad D N$

CASTRO MCC

TRATAMENTO

DE LESÕES DE

CÁRIE PROFUNDA

COM RISCO

DE EXPOSIÇÃO

PULPAR -

DECISÃO BASEADA

EM EVIDÊNCIAS

\section{$164 \ldots$}

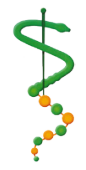

REV, ODONTOL,

UNIV, CID, SÃO

PAULO

2017; $29(2):$ $163-73$, MAI - AGO
A cárie é uma doença biofilme dependente que, no seu estado de lesões ativas não cavitadas, pode ser tratada com o controle dos fatores causadores da doença ${ }^{1}$. No entanto, nas lesões profundas de cárie é necessária a intervenção clínica do profissional de saúde para inativar a lesão e o como proceder tem gerado dúvidas devido ao risco de exposição pulpar durante a remoção da dentina afetada ${ }^{2-4}$.

$\mathrm{Na}$ técnica convencional para o tratamento das lesões de cáries, conhecida como remoção total de cárie, se utiliza o critério de dureza em que o tecido dentinário amolecido é totalmente removido das paredes circundantes e de fundo por se acreditar que, ao se proceder dessa forma, as cavidades estariam livres de bactérias $^{5,6}$. No entanto, estudos recentes demonstraram a presença de colônias de bactérias viáveis em torno de $25-50 \%$ das amostras após a remoção completa do tecido amolecido ${ }^{7,8}$.

O conceito biológico de cárie separa a dentina cariada em duas camadas. A camada mais externa denominada de camada infectada e uma interna denominada afetada. A camada afetada é passível de ser remineralizada por apresentar uma rede de fibrilas colágenas organizada com a presença de cristais de apatita ${ }^{9}$. A remineralização da camada afetada é possível desde que a cavidade esteja totalmente selada do meio externo para que haja a inativação da lesão cariosa ${ }^{10-12}$.

Recentemente, no encontro International Caries Consensus Collaboration, se redigiram as recomendações baseadas nas publicações científicas mais atuais sobre o tratamento e manejo de lesões cariosas médias e profundas. Estudos científicos publicados sobre o assunto foram debatidos e a remoção convencional de tecido cariado foi fortemente questionada ${ }^{13}$.

A remoção de dentina cariada realizada em duas etapas, conhecida como Tratamento Expectante, tem sido sugerida como alternativa menos invasiva, com a finalidade de evitar a exposição pulpar, levando a resultados terapêuticos favoráveis $^{10,14}$. Na primeira sessão se realiza a remoção da dentina mais externa, camada infectada e desorganizada, seguida do selamento temporário da cavidade por 45 a 60 dias, podendo ser estendido até 6 meses. Na segunda sessão, todo o tecido cariado remanescente é removido e a restauração definitiva realizada ${ }^{3,5,6}$.

O desconforto de submeter o paciente a duas sessões clínicas, os avanços científicos sobre a formação e a virulência do biofilme cariogênico, bem como os seus meios de controle, contribuíram para o surgimento da técnica de Remoção Seletiva da dentina cariada ${ }^{15,16}$. Essa técnica consiste na remoção completa da dentina cariada das paredes circundantes, com base no critério de dureza, porém, nas paredes de fundo, axial e pulpar, somente a dentina infectada é removida, seguida da restauração definitiva em uma única sessão ${ }^{4,17}$.

Portanto, a conduta do profissional deve estar firmada em evidências científicas e experiências clínicas. Nesse contexto, o presente estudo tem como objetivo a realização de uma revisão integrativa sobre as formas de tratamento das lesões profundas de cárie em dentes permanentes, que são: a Remoção Total da cárie, o Tratamento Expectante e a Remoção Seletiva da cárie.

\section{MÉ T O D O}

O presente estudo é uma Revisão Integrativa da literatura, método que constitui um instrumento da Prática Baseada em Evidências e que contempla a análise de várias pesquisas sobre determinado assunto, estabelecendo análises comparativas entre as mesmas, a fim de sintetizar o conhecimento e incorporar a aplicabilidade dos resultados de estudos significativos na prática diária ${ }^{18}$. A revisão integrativa foi organizada em seis fases: 1. Identificação do tema e seleção da questão de pesquisa; 2. Estabelecimento de critérios para inclusão e exclusão de estudos; 3. Busca na literatura; 4. Definição das informações a serem extraídas dos estudos selecionados; 5. Avaliação e interpretação dos resultados; 6 . Síntese do conhecimento ${ }^{19}$.

O tema escolhido foi o Tratamento da Cárie Profunda em Dentes Permanentes. A pergunta que motivou esse estudo foi: Como proceder na remoção da cárie muito profunda com risco de exposição pulpar que comprometeria a vitalidade pulpar e 
resistência mecânica do dente? Para o estabelecimento de critérios para inclusão e exclusão de estudos, foram selecionados todos os artigos científicos obtidos a partir dos descritores estabelecidos, publicados em inglês e português, sem limites de ano, que apresentavam o texto completo e disponível nas bases de dados bibliográficas online. Foram excluídas teses, dissertações e monografias.

A pesquisa de artigos na literatura foi re- alizada em periódicos indexados na base eletrônica de dados PubMed/ MEDLINE e BIREME a partir dos descritores em português Cárie Dentária e Restauração Dentária Permanente (e respectivos termos em inglês: Dental Caries e Permanent Dental Restoration. A palavra-chave Tratamento Expectante (ou Expectant Treatment) foi incluída, uma vez que, as buscas somente com os descritores anteriores resultaram em uma seleção de 5.342 artigos científi-

Quadro 1 - Classificação do nível de evidência clínica de acordo com o tipo de estudo e sua definição.

\begin{tabular}{|c|c|c|}
\hline NÍVEL & TIPO DE ESTUDO & DEFINIÇÃO \\
\hline I & $\begin{array}{l}\text { Revisão sistemáti- } \\
\text { ca ou metanálise } \\
\text { ou publicação de } \\
\text { consenso }\end{array}$ & $\begin{array}{l}\text { Estudo com caráter quantitativo ou qualitativo, cujas } \\
\text { estratégias de busca são bem definidas com fontes biblio- } \\
\text { gráficas abrangentes. Os estudos primários são avaliados } \\
\text { segundo critérios rigorosos e reproduzíveis e centrados em } \\
\text { resultados de pesquisas clínicas. }\end{array}$ \\
\hline II & $\begin{array}{l}\text { Estudo descritivo } \\
\text { transversal ou de } \\
\text { prevalência }\end{array}$ & $\begin{array}{l}\text { Fornece dados sobre uma população em um tempo deter- } \\
\text { minado de exposição-doença, a fim de detectar doenças } \\
\text { e/ou fatores de risco e detectar os grupos afetados e não } \\
\text { afetados de uma população. }\end{array}$ \\
\hline III & $\begin{array}{l}\text { Estudo coorte e caso- } \\
\text {-controle }\end{array}$ & $\begin{array}{l}\text { Coorte: estudo onde um grupo de indivíduos expostos ou } \\
\text { não a um fator de interesse é acompanhado em diferentes } \\
\text { espaços de tempo. Caso-controle: comparação entre um } \\
\text { grupo de indivíduos com uma característica clínica de } \\
\text { interesse e um grupo-controle. }\end{array}$ \\
\hline IV & $\begin{array}{l}\text { Estudo clínico rando- } \\
\text { mizado }\end{array}$ & $\begin{array}{l}\text { Tem a conotação de estudo experimental para avaliar uma } \\
\text { intervenção. No ensaio clínico, os participantes são alo- } \\
\text { cados, aleatoriamente, para formar grupos, experimental e } \\
\text { controle, a serem submetidos ou não a uma intervenção. }\end{array}$ \\
\hline V & $\begin{array}{l}\text { Estudos prospectivos } \\
\text { não controlados e } \\
\text { Série de casos }\end{array}$ & $\begin{array}{l}\text { Conjunto de pacientes com um mesmo diagnóstico ou } \\
\text { submetidos à mesma intervenção. Não há grupo-controle } \\
\text { composto. Pode ser utilizado para determinar aspectos de } \\
\text { exposição relativos à doença. }\end{array}$ \\
\hline VI & Relato de caso & $\begin{array}{l}\text { Estudo onde uma investigação da doença ou intervenção é } \\
\text { feita em um único paciente. }\end{array}$ \\
\hline VII & $\begin{array}{l}\text { Revisão narrativa da } \\
\text { literatura }\end{array}$ & $\begin{array}{l}\text { É uma revisão de literatura, cuja fonte de busca e critérios } \\
\text { de seleção de estudos primários não é especificada. Trata- } \\
\text { se de estudo com caráter qualitativo. }\end{array}$ \\
\hline VIII & Pesquisa em animais & $\begin{array}{l}\text { São modelos experimentais empregados em animais de } \\
\text { laboratório com o objetivo de testar um determinado fator } \\
\text { causal ou tratamento previamente à aplicação em huma- } \\
\text { nos. }\end{array}$ \\
\hline IX & $\begin{array}{l}\text { Pesquisa laboratorial } \\
\text { in vitro }\end{array}$ & $\begin{array}{l}\text { Utilização de modelos experimentais em laboratório que } \\
\text { imitam condições biológicas com o teste de novos mate- } \\
\text { riais ou métodos terapêuticos ou preventivos. }\end{array}$ \\
\hline $\mathrm{X}$ & Não classificável & $\begin{array}{l}\text { Não se classifica o nível de evidência clínica de acordo } \\
\text { com o tipo de estudo por não se adequar a nenhuma ca- } \\
\text { racterística. }\end{array}$ \\
\hline
\end{tabular}

Fonte: Adaptado da classificação de Freire e Patussi (2001), Coulter (2003) e Pereira (2013).

VALENTIM VCB

SILVA DN

CASTRO MCC

TRATAMENTO

DE LESÕES DE

CÁRIE PROFUNDA

COM RISCO

DE EXPOSIÇÃO

PULPAR -

DECISÃO BASEADA

EM EVIDÊNCIAS 
VALENTIM VCB

$S I L V A \quad D N$

CASTRO MCC

TRATAMENTO

DE LESÕES DE

CÁRIE PROFUNDA

COM RISCO

DE EXPOSIÇÃO

PULPAR -

DECISÃO BASEADA

EM EVIDENNCIAS

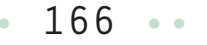

REV, ODONTOL

UNIV, CID , SÃO PAULO

$2017 ; 29(2):$ $163-73$, MA I - AGO cos. Os descritores e palavra-chave foram combinados por meio do conector booleano $E$ em português (ou $A N D$, no idioma inglês). Ao final foram selecionados 16 artigos científicos que contemplavam os critérios de inclusão previamente estabelecidos e atendiam à pergunta norteadora da presente Revisão Integrativa. Para definição das informações a serem extraídas dos estudos, os artigos selecionados foram submetidos a um processo de análise para classificação quanto ao nível de evidência a partir do tipo de delineamento de pesquisa empregado no estudo. As condições para classificação do tipo de estudo foram definidas usando os critérios estabelecidos no Quadro 1, adaptado ${ }^{20-22}$.

Seguindo a metodologia da Prática Baseada em Evidências se procedeu à análise criteriosa dos artigos e interpretação dos resultados, a fim de sintetizar as principais contribuições das publicações em relação ao tema estudado e auxiliar na tomada de decisão diante do questionamento proposto.

RESULTADOS
Tomando como base a classificação

Tabela 1 - Síntese dos periódicos selecionados e classificados quanto ao nível de evidência clínica e considerações temáticas.

\begin{tabular}{|c|c|c|c|}
\hline $\begin{array}{c}\text { AUTORES } \\
\text { ANO }\end{array}$ & $\begin{array}{c}\text { TíTULO DO } \\
\text { ARTIGO }\end{array}$ & $\begin{array}{l}\text { NÍVEL } \\
\text { Tipo de } \\
\text { Estudo }\end{array}$ & CONSIDERAÇÕES TEMÁTICAS \\
\hline $\begin{array}{c}\text { Ricketts et } \\
\text { al. } 2006\end{array}$ & $\begin{array}{l}\text { Complete or } \\
\text { ultra-conserva- } \\
\text { tive removal of } \\
\text { decayed tissue } \\
\text { in unfilled teeth. }\end{array}$ & $\begin{array}{c}\text { NÍVEL I } \\
\text { Revisão- } \\
\text { sistemática }\end{array}$ & $\begin{array}{l}\text { As técnicas de remoção parcial de cárie são } \\
\text { preferíveis à remoção total da cárie devido a } \\
\text { menor risco de exposição pulpar, mas sem evi- } \\
\text { dências se a cavidade deve ser reaberta. Todos } \\
\text { tratamentos não interferiram na progressão da } \\
\text { cárie e na longevidade das restaurações. }\end{array}$ \\
\hline $\begin{array}{c}\text { Ricketts et } \\
\text { al., } 2013\end{array}$ & $\begin{array}{l}\text { Operative caries } \\
\text { management } \\
\text { in adults and } \\
\text { children. }\end{array}$ & $\begin{array}{c}\text { NÍVEL I } \\
\text { Revisão } \\
\text { sistemática }\end{array}$ & $\begin{array}{l}\text { As técnicas de remoção seletiva de cárie e } \\
\text { o tratamento expectante mostram ser clini- } \\
\text { camente mais vantajosas devido à reduzida } \\
\text { incidência de exposições pulpares, compara- } \\
\text { das à técnica de remoção completa da cárie } \\
\text { em dentes permanentes vitais com lesões de } \\
\text { cárie profundas e primárias, mas os estudos } \\
\text { analisados são de curto prazo. }\end{array}$ \\
\hline $\begin{array}{l}\text { Schwendi- } \\
\text { cke et al., } \\
2016\end{array}$ & $\begin{array}{l}\text { Managing } \\
\text { Carious Lesions: } \\
\text { Consensus Rec- } \\
\text { ommendations } \\
\text { on Carious Tis- } \\
\text { sue Removal. }\end{array}$ & $\begin{array}{c}\text { NÍVEL I } \\
\text { Publicação } \\
\text { de consen- } \\
\text { so }\end{array}$ & $\begin{array}{l}\text { Em reunião do International Caries Consensus } \\
\text { Collaboration, os membros recomendaram que } \\
\text { ao restaurar cavidades com cáries profundas a } \\
\text { conservação da polpa deve ser prioridade, e } \\
\text { que a remoção de bactérias e do tecido desmi- } \\
\text { neralizado não é importante. Deve-se realizar a } \\
\text { remoção seletiva da cárie, sendo o tratamento } \\
\text { expectante uma opção de escolha. }\end{array}$ \\
\hline
\end{tabular}

Leksell et after stepwise al.,1996 versus direct complete excavation...

Cost-effectiveSchwendi- ness of caries -cke, Paris, excavations in Stolpe,

2014 different risk groups - a micro-simulation study.
NÍVEL II O tratamento expectante apresentou signifiEstudo pre- cativamente menor prevalência de exposição value prepulpar comparado à remoção total da dentina cariada.

A remoção seletiva de cárie apresentou menor custo e maior eficácia do que o tratamento exNÍVEL III pectante e a remoção completa de cárie independente do risco. Comparando grupos de risco as diferenças foram menores para a escavação seletiva. Todas as três estratégias foram menos eficazes e mais dispendiosas em pacientes com alto risco. 


\begin{tabular}{|c|c|c|c|c|}
\hline $\begin{array}{c}\text { AUTORES } \\
\text { ANO }\end{array}$ & $\begin{array}{c}\text { TíTULO DO } \\
\text { ARTIGO }\end{array}$ & $\begin{array}{l}\text { NÍVEL } \\
\text { Tipo de } \\
\text { Estudo }\end{array}$ & CONSIDERAÇÕES TEMÁTICAS & $\begin{array}{l}\text { VALENTIM VCB } \\
\text { SILVA DN } \\
\text { CASTRO MCC }\end{array}$ \\
\hline $\begin{array}{l}\text { Bjørndal, } \\
\text { Larsen, } \\
\text { Thylstrup, } \\
1997\end{array}$ & $\begin{array}{l}\text { A clinical and } \\
\text { microbiological } \\
\text { study of deep } \\
\text { carious lesion } \\
\text { during stepwise } \\
\text { excavation using } \\
\text { long treatment } \\
\text { intervals. }\end{array}$ & $\begin{array}{l}\text { NÍVEL IV } \\
\text { Estudo } \\
\text { clínico ran- } \\
\text { domizado }\end{array}$ & $\begin{array}{l}\text { Observou-se presença de microrganismos após } \\
\text { remoção total de cárie e após tratamento expec- } \\
\text { tante, mas insuficiente para provocar exposição } \\
\text { pulpar. Clinicamente, observou-se aumento da } \\
\text { dureza da dentina após o tratamento expectan- } \\
\text { te, estando indicada para lesões de cárie pro- } \\
\text { fundas. }\end{array}$ & $\begin{array}{l}\text { DE LESOES DE } \\
\text { CÁRIE PROFUNDA } \\
\text { COM RISCO } \\
\text { DE EXPOSIÇÃO } \\
\text { PULPAR - } \\
\text { DECISÃO BASEADA } \\
\text { EM EVIDENCIAS }\end{array}$ \\
\hline $\begin{array}{l}\text { Maltz et al., } \\
\quad 2012\end{array}$ & $\begin{array}{l}\text { Randomized } \\
\text { trial of partial vs. } \\
\text { stepwise caries } \\
\text { removal: 3-year } \\
\text { follow-up. }\end{array}$ & $\begin{array}{l}\text { NÍVEL IV } \\
\text { Estudo } \\
\text { clínico ran- } \\
\text { domizado }\end{array}$ & $\begin{array}{l}\text { A manutenção da vitalidade pulpar foi significa- } \\
\text { tivamente maior na técnica de remoção seletiva } \\
\text { da cárie comparada ao tratamento expectante } \\
\text { após um período de acompanhamento de } 3 \\
\text { anos. }\end{array}$ & \\
\hline $\begin{array}{l}\text { Bjørndal et } \\
\text { al., } 2010\end{array}$ & $\begin{array}{l}\text { Treatment of } \\
\text { deep caries le- } \\
\text { sions in adults: } \\
\text { randomized } \\
\text { clinical trials } \\
\text { comparing... }\end{array}$ & $\begin{array}{l}\text { NÍVEL IV } \\
\text { Estudo } \\
\text { clínico ran- } \\
\text { domizado }\end{array}$ & $\begin{array}{l}\text { O tratamento expectante diminui o risco de } \\
\text { exposição pulpar, quando comparado com a } \\
\text { remoção completa de cárie. Sendo conside- } \\
\text { rado a melhor escolha pois o prognóstico das } \\
\text { exposições pulpares submetidas ao capeamen- } \\
\text { to direto e pulpotomia foram desfavoráveis. }\end{array}$ & \\
\hline $\begin{array}{l}\text { Maltz et al., } \\
2013\end{array}$ & $\begin{array}{l}\text { Partial removal } \\
\text { of carious } \\
\text { dentine: a } \\
\text { multicenter } \\
\text { randomized } \\
\text { controlled trial } \\
\text { and } 18 \text {-month... }\end{array}$ & $\begin{array}{l}\text { NÍVEL IV } \\
\text { Estudo } \\
\text { clínico ran- } \\
\text { domizado }\end{array}$ & $\begin{array}{l}\text { A preservação da vitalidade pulpar foi mais } \\
\text { eficaz na técnica de remoção seletiva da cárie } \\
\text { do que no tratamento expectante. O procedi- } \\
\text { mento de reabertura da cavidade para remover } \\
\text { a dentina cariada residual infectada não é } \\
\text { necessário. }\end{array}$ & ․ $167 \ldots$ \\
\hline $\begin{array}{l}\text { Bjørndal, } \\
\text { Thylstrup, } \\
1998\end{array}$ & $\begin{array}{l}\text { A practice-based } \\
\text { study on step- } \\
\text { wise excavation } \\
\text { of deep carious } \\
\text { lesions in per- } \\
\text { manent teeth: a } \\
\text { 1-year follow-up } \\
\text { study. }\end{array}$ & $\begin{array}{l}\text { NÍVEL V } \\
\text { Estudo } \\
\text { prospectivo } \\
\text { não contro- } \\
\text { lado }\end{array}$ & $\begin{array}{l}\text { O tratamento expectante foi eficaz quanto à } \\
\text { manutenção da saúde pulpar no tratamente } \\
\text { de lesões de cárie profunda com um ano de } \\
\text { acompanhamento. A dentina se apresentou } \\
\text { significativamente mais dura e com colora- } \\
\text { ção mais escura após o período de selamento } \\
\text { provisório. }\end{array}$ & \\
\hline $\begin{array}{l}\text { Bjørndal, } \\
\text { Larsen, } \\
2000\end{array}$ & $\begin{array}{l}\text { Changes in the } \\
\text { cultivable flora } \\
\text { in deep carious } \\
\text { lesions follo- } \\
\text { wing a stepwise } \\
\text { excavation } \\
\text { procedure. }\end{array}$ & $\begin{array}{l}\text { NÍVEL V } \\
\text { Série de } \\
\text { casos }\end{array}$ & $\begin{array}{l}\text { A microflora cariogênica típica de lesões pro- } \\
\text { fundas detectada na } 2^{\mathrm{a}} \text { sessão do tratamento } \\
\text { expectante foi significativamente menor do } \\
\text { que a observada na } 1^{\mathrm{a}} \text { sessão, quanto ao nú- } \\
\text { mero de colônias e distribuição de espécies de } \\
\text { bactérias, confirmando a paralisação da cárie. }\end{array}$ & \\
\hline $\begin{array}{l}\text { Lima, } \\
\text { Pascotto, } \\
\text { Benetti, } \\
2010\end{array}$ & $\begin{array}{l}\text { Stepwise } \\
\text { excavation in } \\
\text { a permanent } \\
\text { molar: } 17 \text {-year } \\
\text { follow-up. }\end{array}$ & $\begin{array}{l}\text { NÍVEL VI } \\
\text { Relato de } \\
\text { caso }\end{array}$ & $\begin{array}{l}\text { O tratamento expectante é uma boa alternativa } \\
\text { para alguns casos, baseado no diagnóstico de } \\
\text { saúde pulpar, na avaliação dos sinais e sinto- } \\
\text { mas clínicos e radiográficos. }\end{array}$ & \\
\hline $\begin{array}{l}\text { Tora- } \\
\text { bzadeh, } \\
\text { Asgary, } \\
2013\end{array}$ & $\begin{array}{l}\text { Indirect pulp } \\
\text { therapy in a } \\
\text { symptomatic } \\
\text { mature molar } \\
\text { using calcium } \\
\text { enriched mixtu- } \\
\text { re cement. }\end{array}$ & $\begin{array}{l}\text { NÍVEL VI } \\
\text { Relato de } \\
\text { caso }\end{array}$ & $\begin{array}{l}\text { A técnica de remoção seletiva de cárie foi } \\
\text { empregada com sucesso no tratamento de um } \\
\text { dente permanente vital sintomático de pulpi- } \\
\text { te irreversível e periodontite apical em uma } \\
\text { paciente de } 12 \text { anos. Após um ano de acompa- } \\
\text { nhamento o dente se mostrou com vitalidade. }\end{array}$ & $\begin{array}{l}\text { REV. ODONTOL. } \\
\text { UNIV. CID. SÃO } \\
\text { PAULO } \\
2017 ; 29(2): \\
163-73, \text { MAI-AGO }\end{array}$ \\
\hline
\end{tabular}




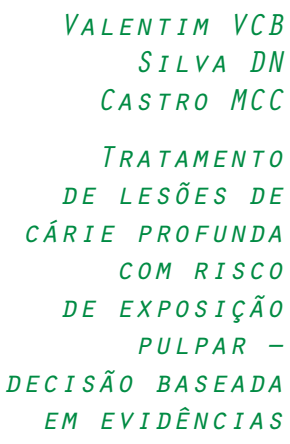

168

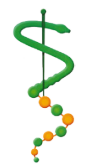

REV. ODONTOL,

UNIV, CID, SÃO

PAULO

2017; 29(2): $163-73$, MAI - AGO

\begin{tabular}{|c|c|c|c|}
\hline $\begin{array}{c}\text { AUTORES } \\
\text { ANO }\end{array}$ & $\begin{array}{c}\text { TÍTULO DO } \\
\text { ARTIGO }\end{array}$ & $\begin{array}{l}\text { NÍVEL } \\
\text { Tipo de } \\
\text { Estudo }\end{array}$ & CONSIDERAÇÕES TEMÁTICAS \\
\hline $\begin{array}{l}\text { Bjørndal, } \\
\text { Kidd, } \\
2005\end{array}$ & $\begin{array}{l}\text { The treatment } \\
\text { of deep dentine } \\
\text { caries lesions. }\end{array}$ & $\begin{array}{l}\text { NÍVEL VII } \\
\text { Revisão } \\
\text { narrativa } \\
\text { da litera- } \\
\text { tura }\end{array}$ & $\begin{array}{l}\text { Estudos microbiológicos e clínicos demonstra- } \\
\text { ram que o número de bactérias diminui duran- } \\
\text { te os procedimentos do tratamento expectante, } \\
\text { e ocorre a inativação da lesão. A dentina des- } \\
\text { mineralizada, amolecida e amarelada se torna } \\
\text { mais endurecida, mais escura e sem umidade. }\end{array}$ \\
\hline $\begin{array}{l}\text { Ricketts, } \\
\text { Pitts, } \\
2009\end{array}$ & $\begin{array}{l}\text { Novel opera- } \\
\text { tive treatment } \\
\text { options. }\end{array}$ & $\begin{array}{l}\text { NÍVEL VII } \\
\text { Revisão } \\
\text { narrativa } \\
\text { da litera- } \\
\text { tura }\end{array}$ & $\begin{array}{l}\text { O selamento de cárie deve ser visto com cau- } \\
\text { tela até que se pesquisem formas seguras de se } \\
\text { monitorar as cáries seladas. Essa técnica é uma } \\
\text { forma alternativa e de marcante potencial de } \\
\text { benefícios para os pacientes em relação à dor, } \\
\text { ao tratamento e ao prognóstico. }\end{array}$ \\
\hline $\begin{array}{l}\text { Manton, } \\
2013\end{array}$ & $\begin{array}{l}\text { Partial caries re- } \\
\text { moval may have } \\
\text { advantages but } \\
\text { limited evidence } \\
\text { on restoration } \\
\text { survival. }\end{array}$ & $\begin{array}{l}\text { NÍVEL VII } \\
\text { Revisão } \\
\text { narrativa } \\
\text { da litera- } \\
\text { tura }\end{array}$ & $\begin{array}{l}\text { O autor fez breve resumo sobre os resultados } \\
\text { da revisão sistemática publicada pela Cochra- } \\
\text { ne Library } 2013 \text { e enfatizou a falta de evidên- } \\
\text { cias científicas marcantes para esta importante } \\
\text { área da prática clínica que afetam diariamente } \\
\text { as condutas clínicas. }\end{array}$ \\
\hline
\end{tabular}

hierárquica de evidência científica, o delineamento metodológico dos estudos analisados mostrou: três artigos nível I, sendo duas revisões sistemáticas e uma publicação de consenso, considerados de forte evidência científica; um estudo de prevalência, classificado no nível II; um estudo de coorte nível III; quatro artigos de estudos randomizados definidos por nível IV; dois estudos considerados de nível $\mathrm{V}$, sendo uma série de casos e um estudo prospectivo não controlado; dois artigos de relatos de caso de nível $\mathrm{VI}$; e três estudos de revisão narrativa da literatura de nível VII, conforme mostra a Tabela1.

A maioria dos estudos selecionados apontam para a não remoção imediata total da cárie. São unânimes em afirmar uma maior manutenção da vitalidade pulpar quando a cárie em lesões profundas não é removida totalmente em dentes que apresentam sinais e sintomas vitais favoráveis $^{4,13,14,16,23-28}$.

A alta prevalência de exposições pulpares em dentes com lesões de cárie profundas em pacientes jovens ficou evidente nos estudos de Leksell et a ${ }^{23}$. (1996), quando se realizou a remoção total de cárie comparada ao tratamento expectante, respectivamente, $40 \%$ e $17 \%$. Esses achados foram corroborados por Bjørndal e
Thylstrup ${ }^{24}(1998)$, por meio de um estudo prospectivo não controlado, que mostraram resultados significativamente favoráveis ao tratamento expectante de dentes com lesões de cárie muito profundas, onde apenas 5 dos 94 dentes permanentes tiveram a polpa exposta.

Desde os primórdios da prática odontológica, a manutenção de tecido cariado era considerada prejudicial para a integridade física e biológica do elemento dental e se preconizava a remoção total da dentina cariada. Entretanto, conceitos arraigados foram alterados pelos estudos de Massler $^{29}$ (1967) e Fusayama ${ }^{30}$ (1979) que fundamentaram a premissa de uma camada de dentina desmineralizada, mas não infectada nas lesões de cárie profundas e que poderia ser passível de remineralização. O conhecimento da presença dessa camada motivou tratamentos da cárie mais conservadores, como o Tratamento Expectante e permitiu a não remoção desnecessária de dentina sadiaa,4,12,13. No entanto, a presença de bactérias persiste nas cavidades após a remoção completa da dentina cariada ou após o tratamento expectante, porém, em ambas as situações insuficientes para provocar a continuidade da lesão ${ }^{14}$. Ao final do Tratamento Expectante são observados resultados 
satisfatórios de consistência e coloração da dentina, isto é, mais dura, mais escurecida e menos úmida, correspondendo a baixas contagens de unidades formadoras de colônia por mililitro de dentina, processo fundamental para a paralisação da lesão ${ }^{5,10}$. Os resultados de ensaios clínicos randomizados, um dos quais acompanhou os pacientes por 10 anos, fornecem fortes evidências para a conveniência de se deixar para trás dentina infectada, cuja remoção iria colocar a polpa em risco de exposição ${ }^{4,14,31}$. Contudo, é necessário salientar que o processo carioso só é interrompido, definitivamente ou gradualmente, se a cavidade estiver isolada adequadamente do ambiente oral, cortando a captação dos nutrientes bacterianos essenciais à sua sobrevivência ${ }^{25,26,28}$. A técnica do Tratamento Expectante apresenta limitações, pois durante o selamento com material restaurador provisório é possível ocorrer contaminação do interior da cavidade por falhas e fraturas marginais, uma vez que esses materiais provisórios não oferecem resistência suficiente às forças mastigatórias por prolongados períodos de tempo. Outra desvantagem é que o paciente e o profissional terão um custo adicional, devido ao retorno para uma segunda sessão ${ }^{15}$.

Os conhecimentos científicos a respeito do comportamento e virulência do biofilme bacteriano, capazes de levar à dissolução dos tecidos dentais, mas pas- síveis de serem controlados não podem mais ser ignorados. A progressão da lesão de cárie é dependente da queda do $\mathrm{pH}$ na cavidade bucal. Aumentos sucessivos de sua intensidade e frequência provocam um desequilíbrio na comunidade bacteriana do biofilme, favorecendo a seleção e multiplicação com dominância dos microrganismos com potencial cariogênico, como os Estreptococos do grupo mutans e os Lactobacilos, comumente encontrados em dominância de $\mathrm{pH}$ menor que 5,51. O sucesso do tratamento de lesões profundas de cárie foi significativamente maior no estudo de coorte realizado por Schwendicke, Paris e Stolpe ${ }^{32}$ (2014), em pacientes submetidos ao Tratamento Expectante com baixo risco de desenvolver cáries devido ao controle da presença de biofilme cariogênico. Contudo, o questionamento se o número de superfícies dos dentes envolvidas influencia no prognóstico não está esclarecido ${ }^{25}$. As lesões de Classe I estão relacionadas à menor acúmulo de placa bacteriana do que as lesões de Classe II, o que facilita o maior controle do biofilme. Maltz et al. ${ }^{31}(2011)$ realizaram um ensaio clínico prospectivo e observaram, após 10 anos de acompanhamento, que dos 16 casos de sucesso 12 eram restaurações Classe I e apenas 4 Classe II, de uma amostra de 26 dentes. Dos 10 dentes que falharam, 8 eram Classe II.

Os conceitos de uma Odontologia Minimamente Invasiva e a adesão dos

Quadro 2 - Estudos randomizados comparando o sucesso do Tratamento Expectante X Remoção Seletiva de cárie.

\begin{tabular}{|l|c|c|c|c|}
\hline \multirow{2}{*}{$\begin{array}{l}\text { AUTORES E ANO DE } \\
\text { PUBLICAÇÃO }\end{array}$} & \multicolumn{2}{|c|}{ ÍNDICE DE SUCESSO (\%) } & \multirow{2}{*}{$\begin{array}{c}\text { TEMPO DE } \\
\text { OBSERVAÇÃO } \\
\text { (ANOS) }\end{array}$} \\
\cline { 2 - 3 } $\begin{array}{c}\text { TRATAMENTO } \\
\text { EXPECTANTE }\end{array}$ & $\begin{array}{c}\text { REMOÇÃO } \\
\text { SELETIVA }\end{array}$ & $n$ & 01 \\
\hline Maltz et al., 2011 & $98 \%$ & $100 \%$ & 154 & 03 \\
\hline Maltz et al., 2012 & $90 \%$ & - & 32 & 10 \\
\hline Maltz et al., 2013 & $93 \%$ & $98 \%$ & 213 & 01 \\
\hline Jardim, Simoneti e & $69 \%$ & $91 \% *$ & 212 & 1,5 \\
\hline Maltz, 2011 & $32 \%$ & $99 \% *$ & 127 & 6 \\
\hline
\end{tabular}

*apresentaram diferença estatística $p<0,05$

VALENTIM VCB

SILVA DN

CASTRO MCC

TRATAMENTO

DE LESÕES DE

CÁRIE PROFUNDA

COM RISCO

DE EXPOSIÇÃO

PULPAR -

DECISÃO BASEADA

EM EVIDÊNCIAS 
VALENTIM VCB

SILVA DN

CASTRO MCC

TRATAMENTO

DE LESÕES DE

CÁRIE PROFUNDA

COM RISCO

DE EXPOSIÇÃO

PULPAR -

DECISÃO BASEADA

EM EVIDÊNCIAS

$170 \ldots$

REV, ODONTOL,

UNIV. CID, SÃO

PAULO:

2017; 29(2):

163-73, MAI - AGO materiais restauradores aos tecidos dentinários têm alterado a proposta de como intervir em cavidades profundas de cárie. Yoshiyama et al.33 (2003) e Say et al. ${ }^{34}$ (2005) observaram a formação de uma camada híbrida mesmo na presença de dentina infectada e bactérias incorporadas ao adesivo. Entretanto, essa condição não afetou o desempenho clínico das restaurações ${ }^{11,13,35}$.

Ricketts et al..$^{25}$ (2006) e Ricketts et al. ${ }^{16}$ (2013), em revisões sistemáticas da literatura, com forte evidência científica, chamaram a atenção para o bom desempenho da Remoção Seletiva, em que a dentina cariada foi parcialmente removida das paredes circundantes e o dente restaurado definitivamente. Dos estudos incluídos na revisão sistemática de 2013, contabilizaram a avaliação de 1372 dentes em 934 pacientes. Os autores observaram redução no número de exposições pulpares de 56\% no Tratamento Expectante e 77\% na Remoção Seletiva comparados à remoção total de cárie. Esse procedimento elimina a necessidade de uma segunda sessão que é realizada no Tratamento Expectante e a possibilidade de insucesso por fraturas do material restaurador provisório. Estudos clínicos randomizados descritos no Quadro 2 confirmam esses dados e mostram alto índice de sucesso em ambas as técnicas conservadoras, sendo mais significativo na Remoção Seletiva 17,26,27,31,36.

As técnicas de Tratamento Expectante e Remoção Seletiva da cárie são formas alternativas de potencial benefício para os pacientes em relação à dor, ao tratamento e ao prognóstico em lesões de cárie primárias profundas ${ }^{2}$, e não fornecem prejuízos para o paciente em termos de sintomas pulpares ${ }^{8,37,38}$. Entretanto, a seleção dos dentes deve seguir critérios rigorosos sobre a condição pulpar para que esses tratamentos mais conservadores sejam in- dicados, que são: sinais positivos de vitalidade pulpar, ausência de patologias periapicais, ausência de pulpite irreversível, testes positivos à percussão ${ }^{3,4}$. Manton ${ }^{28}$ (2013) defende serem necessários mais ensaios clínicos de longo prazo para fortalecimento científico da técnica.

Em 2016, na publicação da International Caries Consensus Collaboration, classificada como de alto nível de evidência clínica, pesquisadores renomados de 12 países recomendaram que o procedimento de reabertura da cavidade para remover a dentina residual infectada não é necessário e que o Tratamento Expectante é uma opção de escolha. Em dentes com cárie profunda que se estenda por mais de $1 / 3$ a $1 / 4$ de dentina, observada radiograficamente, é importante considerar que a remoção do tecido cariado deve criar condições para que a restauração do dente se mantenha por um longo período, preservando a vitalidade pulpar, permitindo a remineralização dos tecidos dentários com bom selamento do meio externo e retardando o ciclo restaurador ${ }^{13}$.

\section{CONCLUSÃO}

No manejo das lesões de cárie profundas com risco de exposição pulpar, as evidências disponíveis suportam que, diante de dentes com teste de vitalidade pulpar positivos e sem alterações radiográficas, deve-se proceder à remoção parcial da cárie e à restauração definitiva do dente por meio das técnicas de Remoção Seletiva ou Tratamento Expectante. É importante o acompanhamento periódico e o controle do biofilme cariogênico, de modo a manter as lesões de cárie inativas e evitar o ciclo restaurador. Observa-se a necessidade de mais estudos com alto nível de evidência clínica, bem delineados, que deem maior suporte à tomada de decisão pelo dentista. 
1. Weyne S, Tuñas I. Cariologia: conceitos de hoje para uma doença de ontem. In: Baratieri LN, editor. Odontologia restauradora: fundamentos e possibilidades. 2 ed. São Paulo: Santos; 2015.

2. Ricketts DN, Pitts NB. Novel operative treatment options. Monographs in oral science. 2009;21:174-87.

3. Lima FF, Pascotto RC, Benetti AR. Stepwise excavation in a permanent molar: 17-year follow-up. Operative dentistry. 2010;35(4):482-6.

4. Bjorndal L, Reit C, Bruun G, Markvart M, Kjaeldgaard M, Nasman P, et al. Treatment of deep caries lesions in adults: randomized clinical trials comparing stepwise vs. direct complete excavation, and direct pulp capping vs. partial pulpotomy. European journal of oral sciences. 2010;118(3):290-7.

5. Bjorndal L, Kidd EA. The treatment of deep dentine caries lesions. Dental update. 2005;32(7):402-4, 7-10, 13.

6. Burnett Jr L, Conceição E. Doença cárie: manifestações clínicas, diagnóstico e terapêutica. In: Conceição $\mathrm{E}$, editor. Dentística, saúde e estética,. 2 ed. Porto Alegre: ArtMed; 2007.

7. Orhan AI, Oz FT, Ozcelik B, Orhan K. A clinical and microbiological comparative study of deep carious lesion treatment in deciduous and young permanent molars. Clinical oral investigations. 2008;12(4):369-78.

8. Lula EC, Monteiro-Neto V, Alves CM, Ribeiro CC. Microbiological analysis after complete or partial removal of carious dentin in primary teeth: a randomized clinical trial. Caries research. 2009;43(5):354-8.

9. Lima JEO. Cárie dentária: um novo conceito. Revista Dental Press de Ortodontia e Ortopedia Facial. 2007;12(6):119-30.
10. Bjorndal L, Larsen T. Changes in the cultivable flora in deep carious lesions following a stepwise excavation procedure. Caries research. 2000;34(6):5028.

11. Doi J, Itota T, Torii Y, Nakabo S, Yoshiyama M. Micro-tensile bond strength of self-etching primer adhesive systems to human coronal carious dentin. Journal of oral rehabilitation. 2004;31(10):1023-8.

12. Corralo DJ, Maltz M. Clinical and ultrastructural effects of different liners/ restorative materials on deep carious dentin: a randomized clinical trial. Caries research. 2013;47(3):243-50.

13. Schwendicke F, Frencken JE, Bjorndal L, Maltz M, Manton DJ, Ricketts D, et al. Managing Carious Lesions: Consensus Recommendations on Carious Tissue Removal. Advances in dental research. 2016;28(2):58-67.

14. Bjørndal L, Larsen T, Thylstrup A. A clinical and microbiological study of deep carious lesions during stepwise excavation using long treatment intervals. Caries research. 1997;31(6):4117.

15. Oliveira EF, Carminatti G, Fontanella $V$, Maltz M. The monitoring of deep caries lesions after incomplete dentine caries removal: results after 14-18 months. Clinical oral investigations. 2006;10(2):134-9.

16. Ricketts D, Lamont T, Innes NP, Kidd E, Clarkson JE. Operative caries management in adults and children. The Cochrane database of systematic reviews. 2013(3):Cd003808.

17. Jardim JJ, Simoneti MND, Maltz M. Remoção parcial de tecido cariado em dentes permanentes: seis anos de acompanhamento. RFO UPF. 2015;20(1):39-45.

18. Souza MT, Silva MD, Carvalho R. Revisão integrativa: o que é e como fazer. Einstein (São Paulo). 2010;8(1):102-6.
VALENTIM VCB

SILVA DN

CASTRO MCC

TRATAMENTO

DE LESÕES DE

CÁRIE PROFUNDA

COM RISCO

DE EXPOSIÇÃO

PULPAR -

DECISÃO BASEADA

EM EVIDÊNCIAS

171

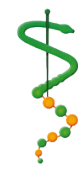

REV. ODONTOL. UnIV. CID, São PAULO 2017; 29(2): 163-73, MAI - AGO 
VALENTIM VCB

$S I L V A \quad D N$

CASTRO MCC

TRATAMENTO

DE LESÕES DE

CÁRIE PROFUNDA

COM RISCO

DE EXPOSIÇÃO

PULPAR -

DECISÃO BASEADA

EM EVIDENNCIAS

172
19. Mendes KDS, Silveira RCdCP, Galvão CM. Revisão integrativa: método de pesquisa para a incorporação de evidências na saúde e na enfermagem. Texto \& Contexto - Enfermagem. 2008;17(4):758-64.

20. Freire M, Patussi M. Tipos de estudo. In: Estrela C, editor. Metodologia científica: ensino e pesquisa em odontologia. São Paulo: Artes Médicas; 2001.

21. Coulter ID. Observational studies and evidence-based practice: Can't live with them, can't live without them. Journal of Evidence Based Dental Practice. 2003;3(1):1-4.

22. Pereira M. Epidemiologia: teoria e prática. 4 ed. Rio de Janeiro: Guanabara Koogan; 2013.

23. Leksell E, Ridell K, Cvek M, Mejare I. Pulp exposure after stepwise versus direct complete excavation of deep carious lesions in young posterior permanent teeth. Endodontics \& dental traumatology. 1996;12(4):192-6.

24. Bjørndal L, Thylstrup A. A practice-based study on stepwise excavation of deep carious lesions in permanent teeth: a 1-year follow-up study. Community dentistry and oral epidemiology. 1998;26(2):122-8.

25. Ricketts D, Kidd E, Innes N, Clarkson J. Complete or ultraconservative removal of decayed tissue in unfilled teeth. The Cochrane database of systematic reviews. 2006;3.

26. Maltz M, Garcia R, Jardim JJ, de Paula LM, Yamaguti PM, Moura MS, et al. Randomized trial of partial vs. stepwise caries removal: 3-year follow-up. Journal of dental research. 2012;91(11):1026-31.

27. Maltz M, Jardim JJ, Mestrinho HD, Yamaguti PM, Podesta K, Moura MS, et al. Partial removal of carious dentine: a multicenter randomized controlled trial and 18-month follow-up results. Caries research. 2013;47(2):103-9.
28. Manton D. Partial caries removal may have advantages but limited evidence on restoration survival. Evidence-based dentistry. 2013;14(3):74-5.

29. Massler M. Pulpal reactions to dental caries. International dental journal. 1967;17(2):441-60.

30. Fusayama T. Two layers of carious dentin; diagnosis and treatment. Operative dentistry. 1979;4(2):63-70.

31. Maltz M, Alves LS, Jardim JJ, Moura Mdos S, de Oliveira EF. Incomplete caries removal in deep lesions: a 10year prospective study. American journal of dentistry. 2011;24(4):211-4.

32. Schwendicke F, Paris S, Stolpe M. Cost-effectiveness of caries excavations in different risk groups - a micro-simulation study. BMC oral health. 2014;14:153.

33. Yoshiyama M, Tay FR, Torii Y, Nishitani Y, Doi J, Itou K, et al. Resin adhesion to carious dentin. American journal of dentistry. 2003;16(1):47-52.

34. Say EC, Nakajima M, Senawongse P, Soyman M, Ozer F, Tagami J. Bonding to sound vs caries-affected dentin using photo- and dual-cure adhesives. Operative dentistry. 2005;30(1):90-8.

35. Ribeiro CC, Baratieri LN, Perdigao J, Baratieri NM, Ritter AV. A clinical, radiographic, and scanning electron microscopic evaluation of adhesive restorations on carious dentin in primary teeth. Quintessence international (Berlin, Germany : 1985). 1999;30(9):5919.

36. Orhan AI, Oz FT, Orhan K. Pulp exposure occurrence and outcomes after 1- or 2-visit indirect pulp therapy vs complete caries removal in primary and permanent molars. Pediatric dentistry. 2010;32(4):347-55.

\footnotetext{
REV. ODONTOL.

UNIV. CID. SÃO

2017; 29(2): 163-73, MAI - AGO
} 
37. Mertz-Fairhurst EJ, Call-Smith KM, Shuster GS, Williams JE, Davis QB, Smith CD, et al. Clinical performance of sealed composite restorations placed over caries compared with sealed and unsealed amalgam restorations. Journal of the American Dental Association (1939). 1987;115(5):689-94.
38. Torabzadeh H, Asgary S. Indirect pulp therapy in a symptomatic mature molar using calcium enriched mixture cement. Journal of conservative dentistry :JCD. 2013;16(1):83-6.

Recebido em 23/01/2017

Aceito em 27/06/2017
VALENTIM VCB SILVA DN CASTRO MCC

TRATAMENTO DE LESÕES DE CÁRIE PROFUNDA COM RISCO DE EXPOSIÇÃO PULPAR DECISÃO BASEADA EM EVIDÊNCIAS

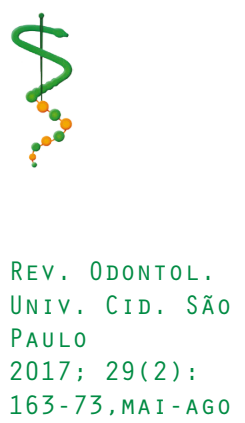

